\title{
TU/e emonownen

\section{Effect of acid pretreatment of the silica substrate on the stability of octadecyl modified reversed phases}

\section{Citation for published version (APA):}

Hetem, M. J. J., Haan, de, J. W., Claessens, H. A., Mussche, P., \& Cramers, C. A. M. G. (1990). Effect of acid pretreatment of the silica substrate on the stability of octadecyl modified reversed phases. Chromatographia, 29(9-10), 473-481. https://doi.org/10.1007/BF02261397

DOI:

10.1007/BF02261397

Document status and date:

Published: 01/01/1990

\section{Document Version:}

Publisher's PDF, also known as Version of Record (includes final page, issue and volume numbers)

\section{Please check the document version of this publication:}

- A submitted manuscript is the version of the article upon submission and before peer-review. There can be important differences between the submitted version and the official published version of record. People interested in the research are advised to contact the author for the final version of the publication, or visit the $\mathrm{DOI}$ to the publisher's website.

- The final author version and the galley proof are versions of the publication after peer review.

- The final published version features the final layout of the paper including the volume, issue and page numbers.

Link to publication

\section{General rights}

Copyright and moral rights for the publications made accessible in the public portal are retained by the authors and/or other copyright owners and it is a condition of accessing publications that users recognise and abide by the legal requirements associated with these rights.

- Users may download and print one copy of any publication from the public portal for the purpose of private study or research.

- You may not further distribute the material or use it for any profit-making activity or commercial gain

- You may freely distribute the URL identifying the publication in the public portal.

If the publication is distributed under the terms of Article 25fa of the Dutch Copyright Act, indicated by the "Taverne" license above, please follow below link for the End User Agreement:

www.tue.nl/taverne

Take down policy

If you believe that this document breaches copyright please contact us at:

openaccess@tue.nl

providing details and we will investigate your claim. 


\title{
Effect of Acid Pretreatment of the Silica Substrate on the Stability of Octadecyl Modified Reversed Phases
}

\author{
M. Hetem ${ }^{1 *} /$ J. de $\operatorname{Haan}^{1} /$ H. Claessens ${ }^{1} / \mathrm{Ph}$. Mussche ${ }^{2} /$ C. Cramers ${ }^{1}$ \\ ${ }^{1}$ Eindhoven University of Technology, Department of Chemical Technology, Laboratory of Instrumental Analysis, \\ P.O. Box 513, NL-5600 MB Eindhoven, The Netherlands \\ ${ }^{2}$ Chrompack International B.V., P.O. Box 8033, NL-4330 EA Middelburg, The Netherlands
}

\section{Key Words \\ Column liquid chromatography \\ Stability of reversed phases \\ Acid pretreatment of silica \\ Solid state ${ }^{29} \mathrm{Si}$ NMR \\ Crystalline regions}

\begin{abstract}
Summary
Two stationary phases, identically modified and derived from the same experimental Chromspher substrate, but one of which has been pretreated with a hydrofluoric acid solution, are compared after ageing with various eluents under simulated routine conditions. The hydrothermal hydrofluoric acid treatment of the silica substrate prior to modification with dimethyloctadecyl-silane improved both the surface coverage and the stability of the resulting stationary phase compared to those of the original substrate. The stability of the silica-to-silane bonding after modification was characterized by means of chromatographic techniques and elemental analysis. Changes in the rigidity of the substrate were studied by means of solid state ${ }^{29} \mathrm{Si}$ NMR. The effect of the hydrothermal acid treatment on relevant substrate parameters, including formation of crystalline regions at the surface, is also discussed.
\end{abstract}

\section{Introduction}

One of the major problems yet to be solved with chemically modified stationary phases for use in reversed phase liquid chromatogrphy (RP-HPLC) is the deterioration of these phases in the course of routine use with relatively agressive eluents [1-3]. The long term stability of these stationary phases in laboratory practice is limited by hydrolysis of ligands from the surface and hydrolysis of the silica substrate [4-6]. The use of aqueous buffer solutions with $\mathrm{pH}$ values below 3 or above 8 and eluents with a relatively high salt content drastically decrease the useful lifetime of RP-HPLC columns $[1,4,6]$.
Currently some manufacturers apply special hydrothermal treatments to silica substrates, thus giving the surface new physical or/and chemical properties, in order to improve their proprietary stationary phases. Here, we report on a study into the changes in surface properties brought about by a hydrothermal acidic treatment of the silica substrate before modification. The effect of this treatment on the stability of modified octadecyl silane ligands is studied by ageing these phases under conditions which simulate routine use. Changes in properties after ageing are characterized and partially quantified as reported in earlier publications $[4,6]$.

The two different octadecylsilane RP-HPLC stationary phases discussed here were prepared from a single starting silica substrate. Part of this substrate was pretreated with a $0.1 \%(w / w)$ hydrofluoric acid solution in order to increase the reactivity of the silanol groups at the surface towards modification with octadecyl silanes. The second stationary phase was synthesized on the original substrate. The hydrothermal acidic treatment altered some important surface properties, as witnessed by an increase in the silanediol/silanol ratio and ligand density after subsequent modification. We also found inhomogeneous areas of small crystalline micro-structures at the surface of the pretreated substrate. In this work the pretreatment with hydrofluoric acid resulted in an increased ligand density of about 30 percent. It may be concluded that the resistance to ligand hydrolysis of the pretreated octadecyl reversed phase, when exposed to ageing, was superior to that of the non-pretreated stationary phase.

\section{Experimental}

\begin{abstract}
Materials
The test components used for chromatographic characterization were all of reference grade. The alkylbenzenes used (test mixture 1) were benzene, methylbenzene, ethylbenzene, propylbenzene, and butylbenzene. The alkyl aryl ketones used (test mixture 2) as test compounds were ethanophenone, propanophenone, butanophenone, pentanophenone, hexanophenone and octanophenone (Pierce Chemical
\end{abstract}


Corp., Rockford, IL, USA). All other solvents and chemicals used, both in simulating routine experiments and in chromatographic characterization, were of analytical grade (E. Merck, Darmstadt, FRG.). The deionized water exhibited an electrical resistance exceeding 10 Mohm. $\mathrm{cm}^{-1}$, (Milli-Q system, Millipore Corp., Bedford, USA). All eluents were freshly prepared and filtered through $0.22 \mu \mathrm{m}$ membrane filters (Millipore Corp., Bedford, USA) prior to use.

\section{Chromatography}

The two octadecyl stationary phases which form the subject of this study were produced by modification of the same substrate, an experimental Chromspher silica (Chrompack B.V., Middelburg, NL). Part of the silica that had been hydrated according to standard procedures was dehydrated at $450^{\circ} \mathrm{C}$. Subsequent hydrothermal treatment with a $0.1 \%(w / w)$ solution of hydrofluoric acid in deionized water at $95^{\circ} \mathrm{C}$ for 2 hours, increased the amount of the more reactive geminal silanol groups, $\mathrm{Q}_{2}$-groups, at the silica surface and drastically decreased the amount of ionic impurities present in the substrate (see Table I). The two substrates, untreated and pretreated, were modified with dimethylamine-dimethyloctadecylsilane (DMADMODS) $[7,8]$ under identical experimental conditions. An excess of the mono-reactive silane was dissolved in $n$-pentane and added to the silica substrate under an atmosphere of nitrogen. The n-pentane was removed by evacuation and, subsequently, the reaction mixture was refluxed at $220^{\circ} \mathrm{C}$ under a nitrogen atmosphere for 18 hours. The modified silicas were then filtered and thoroughly washed successively with n-pentane, dry acetone and methanol. The two reversed phase silicas thus prepared are referred to in the following discussion as octadecyl Chromspher silica (ODCS) and pretreated octadecyl Chromspher silica (PODCS), respectively. The bulk properties of the modified stationary phases are listed in Table II. The carbon content of the modified $\mathrm{C}_{18}$ stationary phases, prior to and after simulated routine use, was obtained with a Perkin Elmer Analyzer, model 240 (Perkin Elmer Corp., Norwalk, CT, USA).

Each stationary phase was used to pack seven identical Swagelock columns, $100 \mathrm{~mm} \times 4.6 \mathrm{~mm}$, i.d. (Crawford Fitting Company, Solon, OH, USA.) according to a standard packing procedure. After a chromatographic test to ensure reproducibility of the packing procedure six columns were placed in an apparatus for simulated routine use, while the remaining column was used as a reference column for initial chromatographic characterization. The equipment and procedure for simulated intensive routine use have been formerly described in detail [4]. The basic and acidic aqueous and methanol/aqueous buffers used for ageing were identical as before [6], see Table III. After ageing, the columns were subjected to chromatographic characterization as previously extensively discussed [6], with the two series of homologues, alkylbenzenes and alkyl aryl ketones, at suitable eluent compositions. These chromatographic experiments were performed with a model $100 \mathrm{~A}$ pump (Beckman Instruments,
Table I Bulk properties of the two silica substrates prior to silane modification; $\mathrm{A}=$ untreated Chromspher silica, $B=$ Chromspher silica after the hydrothermal acidic treatment.

\begin{tabular}{|c|c|c|}
\hline & Silica A & Silica B \\
\hline Mean particle size $(\mu \mathrm{m})$ & $5 \pm 1.5$ & $5 \pm 1.8$ \\
\hline Mean pore size $(\mathrm{nm})$ & 7 & 7,5 \\
\hline$S_{B E T}$, Specific area $\left(\mathrm{m}^{2} / \mathrm{g}\right)$ & 152 , & 141 \\
\hline Pore volume $\left(\mathrm{cm}^{3} / \mathrm{g}\right)$ &, 51 &, 50 \\
\hline \multicolumn{3}{|l|}{ Ion content (ppm) (1) } \\
\hline - Sodium: & 4200 & 1500 \\
\hline - Aluminum: & 400 & 300 \\
\hline - Iron: & 190 & 130 \\
\hline $\begin{array}{l}\text { - Nickel: } \\
\text { relative silanol ratio (2) }\end{array}$ & 20 & 50 \\
\hline - vicinal/"lone": & 1,00 & 0,88 \\
\hline - geminal: & - & 0,12 \\
\hline
\end{tabular}

(1) determined by atomic absorption spectrometry (AAS); calcium and copper content below $5 \mathrm{ppm}$.

(2) determined by solid state ${ }^{29} \mathrm{Si}$ MAS NMR.

Table II Bulk properties of the octadecylsilane modified RP-HPLC stationary phases under study; ODCS = synthesized on silica $\mathrm{A}$, PODCS = synthesized on silica $B$.

\begin{tabular}{|lcc|}
\hline & ODCS & PODCS \\
\hline Mean particle size $(\mu \mathrm{m})$ & $5 \pm 1.5$ & $5 \pm 1.8$ \\
Mean pore size $(\mathrm{nm})$ & 6, & 6, \\
S $_{\text {BET }}$ Specific area $\left(\mathrm{m}^{2} / \mathrm{g}\right)$ & 93, & 87, \\
Pore volume $\left(\mathrm{cm}^{3} / \mathrm{g}\right)$ & 0,285 & 0,286 \\
Ion content $(\mathrm{ppm})(1)$ & & \\
- Sodium: & 1500, & 200, \\
- Aluminum: & 200, & 100, \\
- Iron: & 120, & 110, \\
- Nickel: & 50, & 100, \\
Carbon content $\mathrm{P}_{\mathrm{c}}(\mathrm{w} / \mathrm{w}) \%(2)$ & 10,06 & 11,59 \\
Ligand surface density & & \\
$\alpha_{1}$ (see [6], eq. (1) $\left(\mu \mathrm{mol} \cdot \mathrm{m}^{-2}\right)$ & 3,16 & 4,03 \\
\hline
\end{tabular}

(1) determined by AAS; calcium and copper content below 5 ppm.

(2) determined by elemental analysis.

Berkeley, CA, USA), a model CV-6-VHPa-N60 injection valve equipped with a $20 \mu$ l loop (Valco, Houston, TX, USA) and a model LC-3 variable wavelength UV-detector (Pye Unicam, Cambridge, UK) operated at $254 \mathrm{~nm}$. Typically volumes of 5-10 $\mu \mathrm{l}$ of the test mixtures were injected. The detector signal was sampled at $10 \mathrm{~Hz}$ and integrated with a Nelson 3000 data system (Nelson Analytical, Cupertino, CA, USA).

\section{Solid State ${ }^{29}$ Si CP-MAS NMR Measurements}

The solid state ${ }^{29} \mathrm{Si}$ NMR spectra were obtained on a Bruker CXP 300 Fourier transform NMR spectrometer at $59.63 \mathrm{MHz}$. Representative samples of $180-$ 
Table III Eluent compositions for experiments simulating routine use. Each column purged by 7000 column volumes of a typical eluent; flow-rate $0.5 \mathrm{ml} / \mathrm{min}$; time $240 \mathrm{~h}$; ambient temperature.

\begin{tabular}{|clccc|}
\hline $\begin{array}{c}\text { Ageing } \\
\text { experiment no. }\end{array}$ & Buffer & $\mathrm{pH}$ & $\begin{array}{c}\text { Volume fraction of } \\
\text { methanol in the ageing } \\
\text { eluent }\end{array}$ & $\begin{array}{c}\text { Ion pairing agent } \\
\text { concentration 5 mMol }\end{array}$ \\
\hline 1 & 0.05 M Phosphate & 3.0 & 0 & - \\
2 & 0.05 M Phosphate & 3.0 & 0.5 & - \\
3 & 0.05 M Phosphate & 3.0 & 0.5 & Hexylsulfonate \\
4 & 0.05 M Carbonate & 8.4 & 0 & - \\
5 & 0.05 M Carbonate & 8.4 & 0.5 & Triethylamine \\
\hline
\end{tabular}

$220 \mathrm{mg}$ were spun at ca. $3.5 \mathrm{kHz}$ using aluminum oxide rotors of the standard Bruker double bearing type. Solid state ${ }^{29} \mathrm{Si}$ cross-polarization magic angle spinning (CP-MAS) NMR spectra of all the modified $\mathrm{C}_{18}$ stationary phases prior to and after simulated routine treatments were obtained with a cross-polarization contact time of $6 \mathrm{~ms}$. For the ${ }^{29} \mathrm{Si}$ CP-MAS NMR spectra of both silica substrates a contact time of $2 \mathrm{~ms}$. was applied. A spin-temperature-alternated $\mathrm{CP}$ sequence with quadrature cycling and flip-back of the ${ }^{1} \mathrm{H}$ nuclei was applied to eliminate experimental artifacts. The pulse interval was $1 \mathrm{~s}$.

Typically 2000 free induction decays (FIDs) with an acquisition time of $10 \mathrm{~ms}$. were accumulated in $1 \mathrm{~K}$ data points, zero filled to $8 \mathrm{~K}$ prior to Fourier transformation. The line broadening used was $20 \mathrm{~Hz}$ prior to zero-filling and Fourier transformation. The spectral width for all spectra was $20 \mathrm{kHz}$. The different types of surface silane/siloxane groups, with their ${ }^{29} \mathrm{Si}$ NMR chemical shifts, present at the surface have already been reported [6]. Experiments with variable contacts measuring the characteristic $\mathrm{CP}$-behaviour were carried out for both silica substrates and the two octadecyl modified reversed phases. Series of nineteen contacts ranging from 0.1 to $40 \mathrm{~ms}$ were applied. To eliminate time dependent artifacts block averaging was used. Typically $16 \times 64$ FIDs were accumulated for each contact. The other spectral parameters were as described above. For a quantitative comparison ${ }^{29} \mathrm{Si}$ Bloch decay magic angle spinning (MAS) NMR spectra of both silica substrates were obtained with a pulse interval of $90 \mathrm{~s}$ and typically 1000 FIDs were accumulated.

\section{Results and Discussion}

\section{Characterization}

\section{Solid State ${ }^{29}$ Si NMR}

The solid state ${ }^{29} \mathrm{Si}$ CP-MAS NMR spectra of both Chromspher substrates and their modified $\mathrm{C}_{18}$ reversed phases before and after simulated routine use are shown in Figures 1 and 2. The structures of the siliceous moieties most relevant to this paper are depicted in Figure 3.

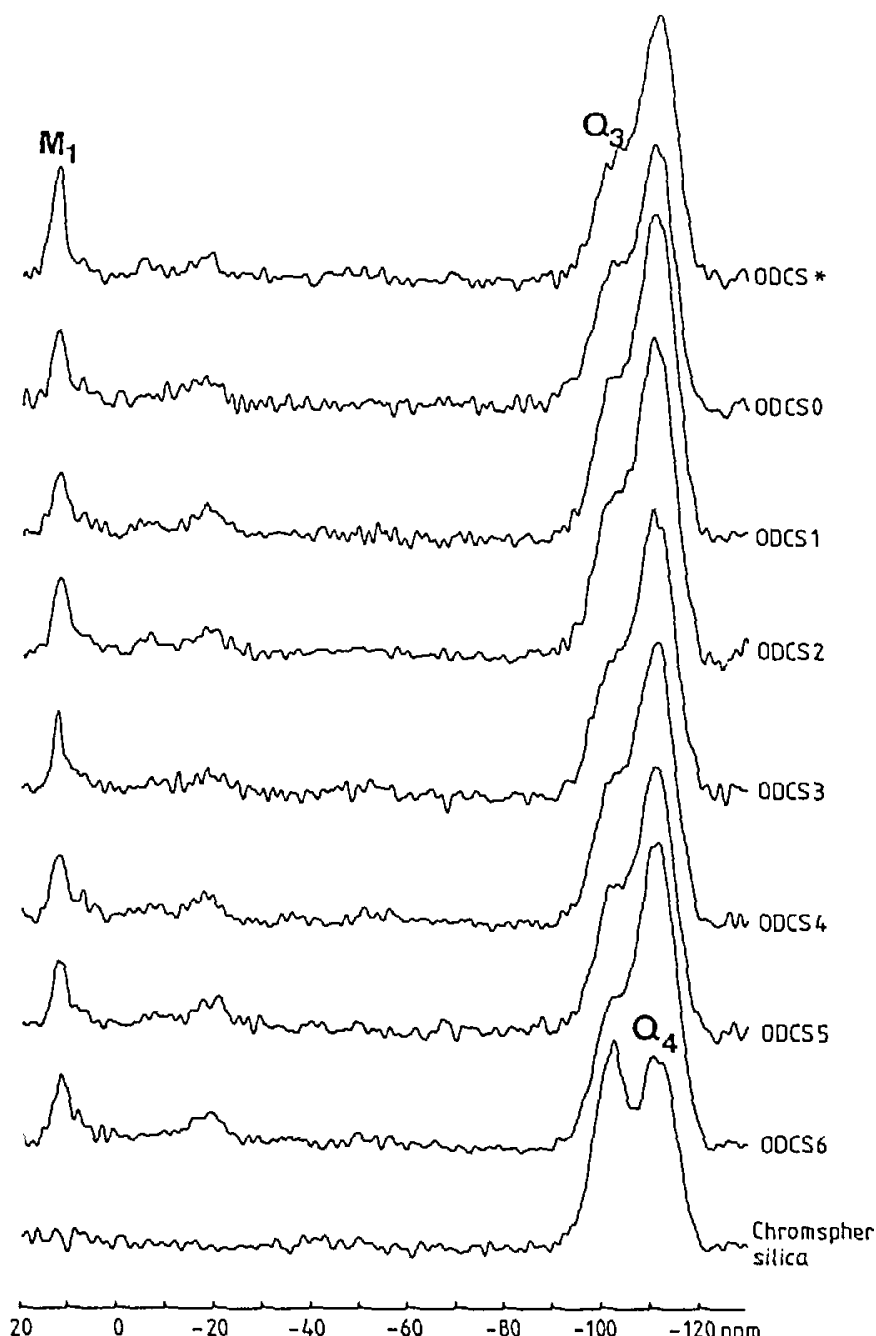

Figure 1

${ }^{29} \mathrm{Si}$ CP-MAS NMR spectra of the Chromspher silica substrate and ODCS phases before and after each treatment. Ns $=2000$, contact time $6 \mathrm{~ms}$., pulse interval time $1 \mathrm{~s}$., acquisition time $10 \mathrm{~ms}$., line broadening $20 \mathrm{~Hz}$.

The roman numerals indicate the typical ageing experiments as outlined in Table III.

From these spectra the relative surface concentration of all siliceous moieties can be calibrated. The results of spectroscopic measurements and elemental analysis are summarized in Tables IV and V for our untreated and treated substrates respectively. Although the 


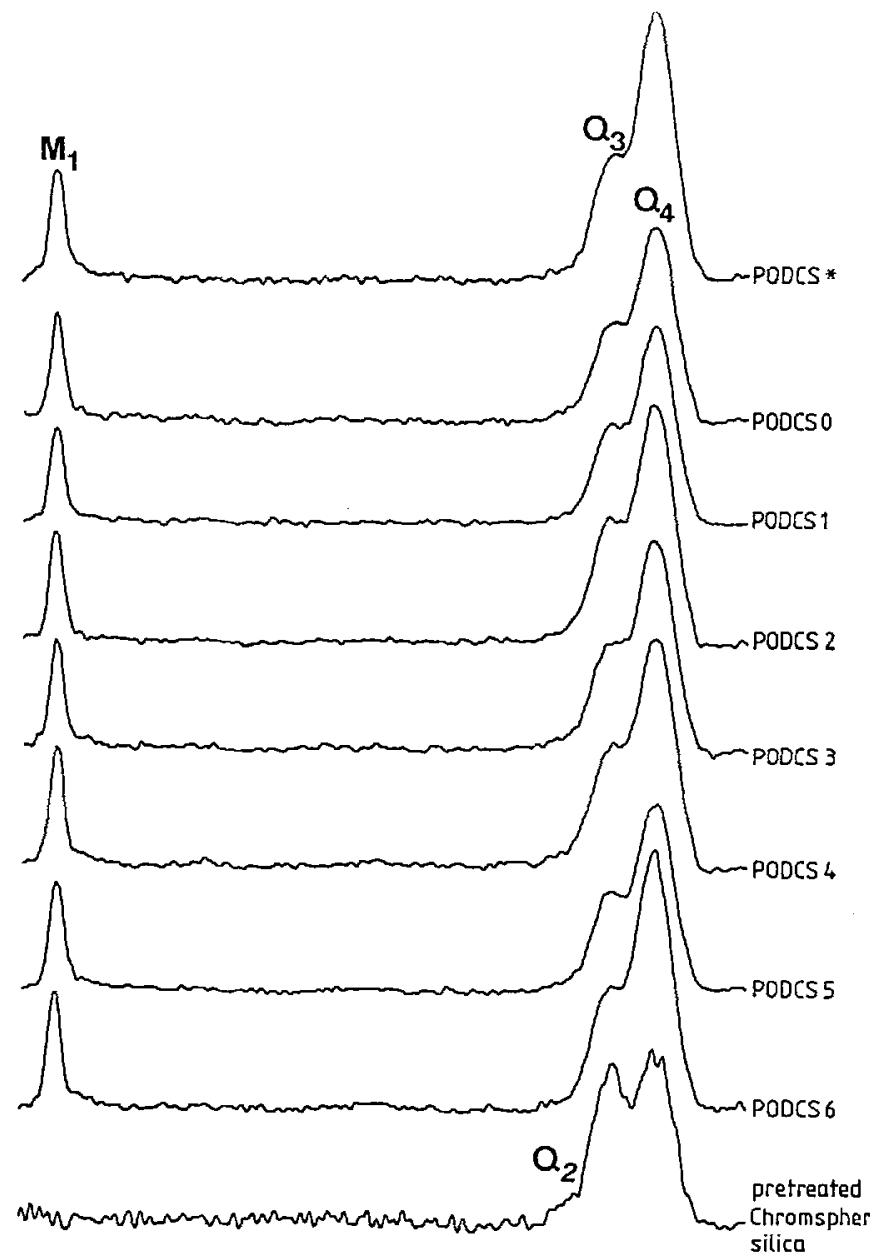

$\begin{array}{llllllll}20 & 0 & -20 & -40 & -60 & -80 & -100 & -120 \mathrm{ppm}\end{array}$

Figure 2

${ }^{29} \mathrm{Si}$ CP-MAS NMR spectra of the pretreated Chromspher silica substrate and PODCS phases before and after each treatment. Ns = 2000 , contact time $6 \mathrm{~ms}$., pulse interval time $1 \mathrm{~s}$., acquisition time 10 ms., line broadening $20 \mathrm{~Hz}$. The roman numerals indicate the typical ageing experiments as outlined in Table III.
Monofunctionel silanes

Tetrafunctional siloxanes

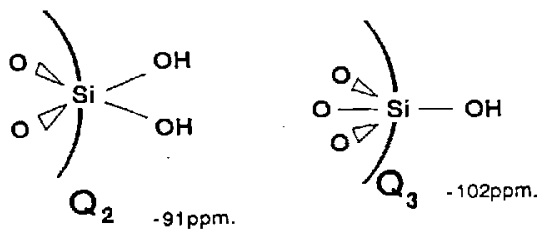

Figure 3

Structure of siliceous moicties most relevant to this paper, notation and ${ }^{29}$ Si chemical shift.

results from neither the elemental analysis nor the solid state ${ }^{29} \mathrm{Si}$ CP-MAS NMR show a perfect match the results for both methods before and after the simulation of intensive use show a fair agreement. It is clear that the density of ligands at the surface upon modification was increased due to the preceding hydrothermal hydrofluoric acidic treatment. The origin of this phenomenon is the formation of more reactive geminal silanol groups $\left(\mathrm{Q}_{2}, 12 \%\right.$ more) during this pretreatment. These geminal silanols are formed when siloxane bridges at the surface of the silica substrate are extensively hydrolysed.

As studied by Lork [9] hydrothermal acidic treatments of "soft" silica gels may very well introduce small hexagonal crystalline domains most probably $\beta$ tridymite, at the surface. In particular, a high level of

Table IV Results of elemental analysis and solid state ${ }^{29}$ Si CP-MAS NMR experiments of the ODCS stationary phase before and after simulating routine use experiments. The number indicates the typical ageing experiment as given in Table III. The ODCS* and ODSC0 phase denote the original stationary phases before and after packing/chromatographic characterization, respectively.

\begin{tabular}{|lcccc|}
\hline & relative \% Carbon & $\begin{array}{c}\text { Ligand density } \\
\alpha_{1}(\mathrm{eq} .1[6] \\
\left(\mu \mathrm{mol} \cdot \mathrm{m}^{-2}\right)\end{array}$ & $\mathrm{M}_{1}$ & $\mathrm{Q}_{3}$ \\
\hline ODCS* & 10.06 & 3.16 & 0.44 & 0.56 \\
ODCS0 & 9.07 & 2.77 & 0.37 & 0.63 \\
ODCS1 & 8.74 & 2.69 & 0.23 & 0.77 \\
ODCS2 & 8.79 & 2.71 & 0.32 & 0.68 \\
ODCS3 & 8.84 & 2.73 & 0.33 & 0.67 \\
ODCS4 & 8.65 & 2.66 & 0.25 & 0.75 \\
ODCS5 & 8.46 & 2.60 & 0.31 & 0.69 \\
ODCS6 & 8.51 & 2.62 & 0.33 & 0.67 \\
\hline R.D. (eq. 7 [6]): & & $3.67 \%$ & $20.3 \%$ & \\
\hline
\end{tabular}


Table V Results of elemental analysis and solid state ${ }^{29} \mathrm{Si}$ CP-MAS NMR experiments of the PODCS stationary phase before and after each ageing experiments. Experimental conditions as outlined in Table III.

\begin{tabular}{|lcccc|}
\hline & relative \% Carbon & $\begin{array}{c}\text { Ligand density } \\
\alpha \text { ( }(\mathrm{eq} .1[6]) \\
\left(\mu \mathrm{mol} \cdot \mathrm{m}^{-2}\right)\end{array}$ & $\mathrm{M}_{1}$ & $\mathrm{Q}_{3}$ \\
\hline PODCS* & 11.59 & 4.03 & 0.59 & 0.41 \\
PODCS0 & 11.35 & 3.93 & 0.57 & 0.43 \\
PODCS1 & 11.08 & 3.81 & 0.51 & 0.49 \\
PODCS2 & 10.96 & 3.77 & 0.50 & 0.50 \\
PODCS3 & 10.95 & 3.77 & 0.52 & 0.48 \\
PODCS4 & 11.30 & 3.91 & 0.56 & 0.44 \\
PODCS5 & 11.17 & 3.85 & 0.53 & 0.47 \\
PODCS6 & 11.27 & 3.89 & 0.49 & 0.51 \\
\hline R.D. (eq. 7 [6]): & & $2.46 \%$ & $9.10 \%$ & \\
\hline
\end{tabular}

ionic impurities, as we have in the present case, will enhance the formation and stability of the $\beta$-tridymite domains. Feher et al. [10] reported the formation of $\beta$ tridymite-like structures from heptameric-trisilanol structures. In our opinion the leaching of silicas with relatively high impurity levels could also lead to heptameric-hexasilanol, and consequently to $\beta$-tridymite crystalline microstructures, at the surface. This phenomenon is also consistent with the $\mathrm{CP}$-behaviour [11] of the ${ }^{29} \mathrm{Si}$ nuclei, as depicted in Figure 4 and Figure 5 for the substrates and the monofunctionally modified reversed phases respectively.

The initial rise on the left side of each plot is due to the growth of ${ }^{29} \mathrm{Si}$ magnetization due to crosspolarization by protons with a characteristic time $T_{\mathrm{HSi}}$, and the subsequent decline is caused by relaxation of spin-locked protons with a spin-lattice relaxation time in the rotating frame, $T_{1 \mathrm{pH}}$. Both the magnetization rise and decline of the "lone" and vicinal silanol groups, $\mathrm{Q}_{3}$, and substrate siloxanes, $\mathrm{Q}_{4}, \mathrm{CP}$-curves, at -102 ppm and -110.5 ppm respectively, of the Chromspher silica show an approximately single exponential behaviour [11, 12]. The same is true for the dimethyloctadecylsiloxysilane, $\mathrm{M}_{1}$, moiety (at +12 $\mathrm{ppm}$ ), and the $\mathrm{Q}_{3}$ and $\mathrm{Q}_{4} \mathrm{CP}$ curves of the monofunctionally octadecylsilane modified Chromspher silica.

The CP-behaviour of hydrothermal acid treated Chromspher silica and the derived octadecyl stationary phase is completely different. Here, shoulders or double maxima were determined, indicating surface areas with different crosspolarization behaviour. We assume the coexistence of at least two different regions present at the surface: amorphous silica, with relatively large $T_{\mathrm{HSi}}$, and $\mathrm{T}_{1 \mathrm{pH}}$ values, and crystalline micro-structures, $\beta$-tridymitelike, with small $T_{\mathrm{HSi}}$, and $\mathrm{T}_{1 \mathrm{pH}}$ values. This hypothesis

Figure 4

Characteristic CP-bchaviour of ${ }^{29} \mathrm{Si}$ atoms in Chromspher silica [A] and hydrothermally acidic treated Chromspher silica [B]. - - Q3:-102 ppm; - $-\mathrm{Q} 4:-110 \mathrm{ppm}$.
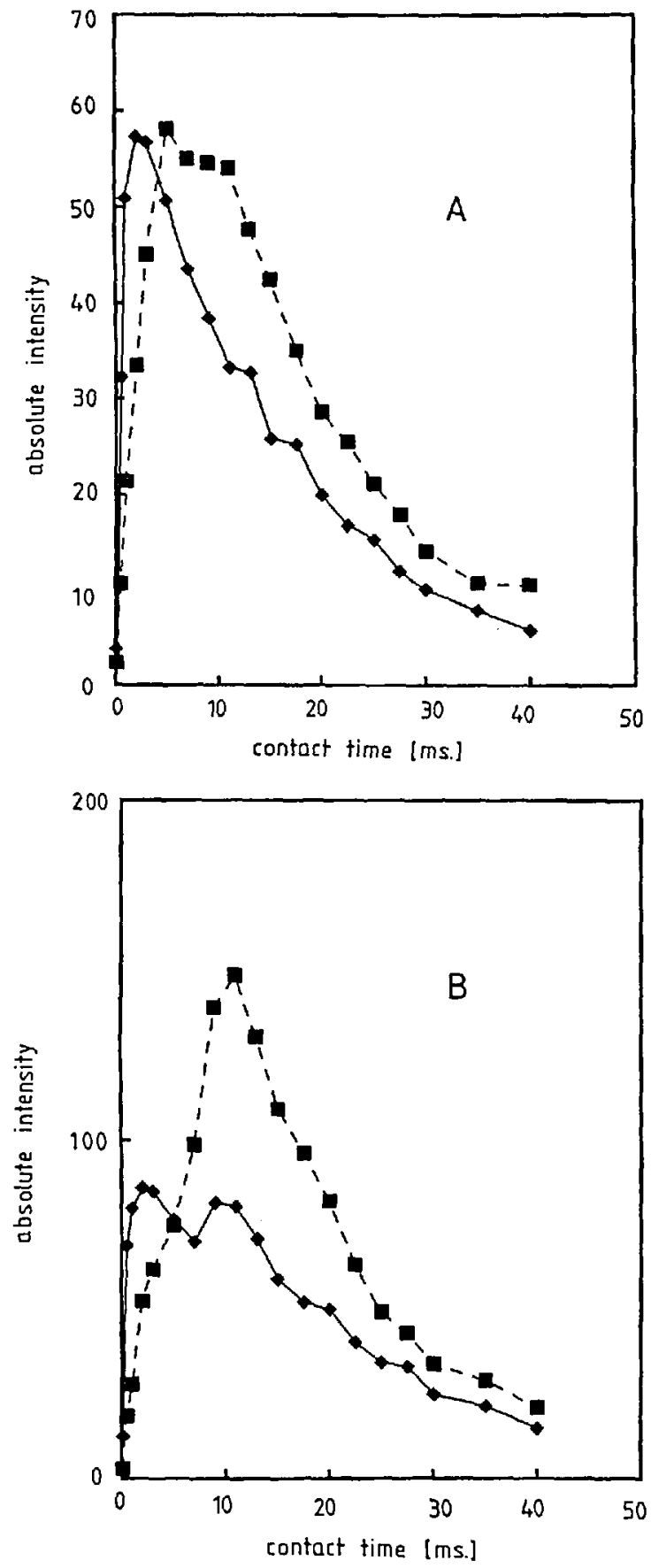

Originals 

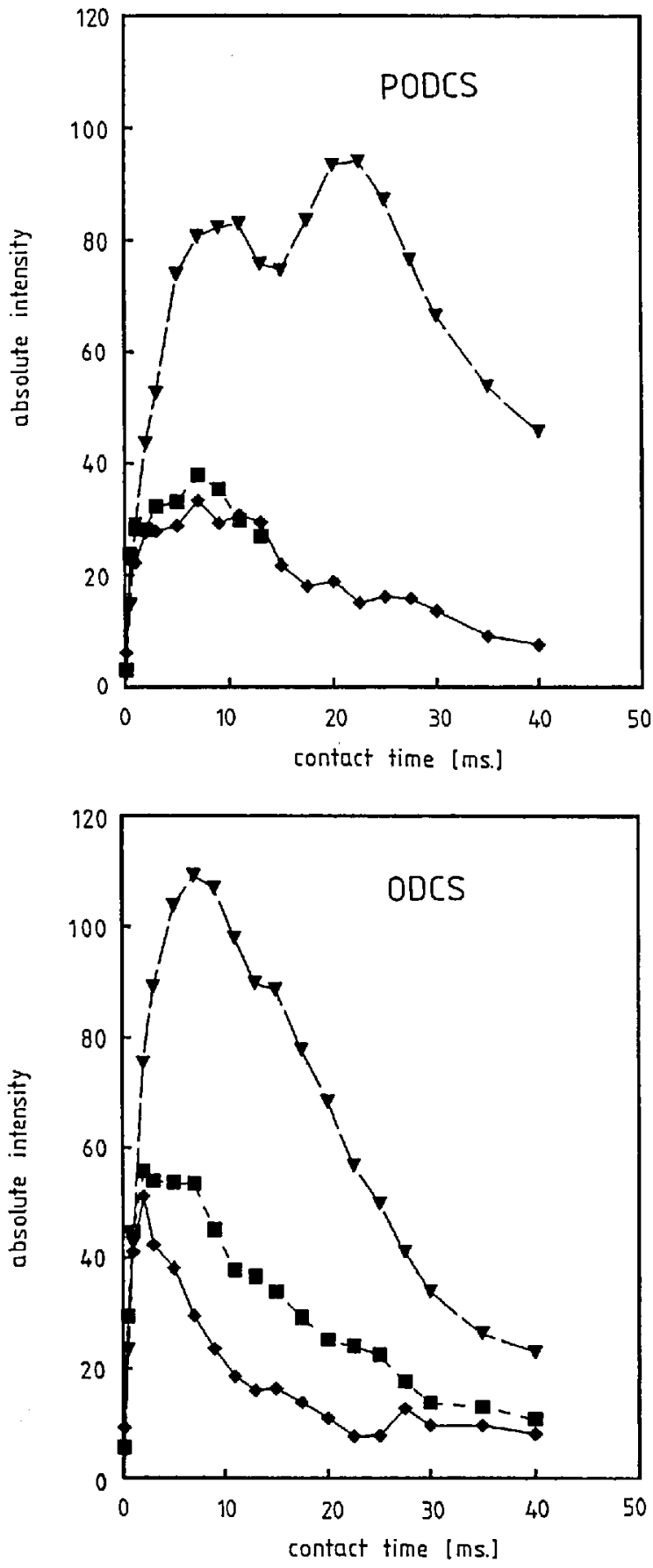

Figure 5

Characteristic CP-behaviour of ${ }^{29} \mathrm{Si}$ nuclei in ODCS and PODCS stationary phascs.

- - + $12 \mathrm{ppm} ;---102 \mathrm{ppm} ;-\nabla--110 \mathrm{ppm}$.

is in agreement with the considerable wash out of foreign ions from the silica substrate (mainly sodium ions) by the hydrothermal acidic treatment.

Both elemental analysis and solid state ${ }^{29} \mathrm{Si}$ CP-MAS NMR measurements of the two stationary phases ODCS and PODCS showed a loss of ligands after exposure to the ageing eluents due to stationary phase stripping. However, the ODCS phase had already lost a considerable amount of alkyl chains during the packing procedure and subsequent chromatographic characterization (before packing: ODCS* and after characterization: ODCS0). This drop in organic content is probably caused by the wash out of unreacted physically adsorbed silane ligands at the surface after modification with an excess of these silanes. Therefore, the concentration of ligands depicted for both phases after chromatographic characterization, treatment 0 , should be taken as the reference for further comparison.

The relative deviation (RD) of the reported values, see Tables IV and V, were calibrated by comparing the values determined before and after ageing treatments relative to the value before, as calibrated by Eq. (7) [6]. The $R D$ values for both ligand density and relative $\mathrm{M}_{1}$ ratio were higher for the ODCS phase than for the PODCS phase. The PODCS phase exhibited a better resistance towards hydrolysis of the chemically bonded ligands, especially for eluents with high $\mathrm{pH}$ values (ageing experiments 4 to 6).

The RD values calculated were smaller for elemental analysis than for ${ }^{29} \mathrm{Si}$ CP-MAS NMR. This is mainly caused by fundamental differences between the two methods, as discussed before [6]. The determination of the amount of carbon relative to the amount of silica will be influenced by concurrent hydrolysis of the silica substrate. Surface analysis with ${ }^{29} \mathrm{Si}$ CP-MAS NMR includes also the analysis of the increasing amount of silanol groups after hydrolysis of ligands and substrate siloxane bonds. The large amount of silanol, mostly $\mathrm{Q}_{3}$ sites, inevitably influences the ratio of $M_{1}$ to $Q_{3}$ given in Tables IV and $V$. In this case the $R D$ value will be relatively large.

\section{Chromatography}

From the chromatograms of alkylbenzenes (test mixture 1) and alkyl aryl ketones (test mixture 2) the capacity factors were determined before and after the ageing experiments. Also for each column the separation efficiency, N(sys), was calculated for butylbenzene eluted with an aqueous methanol eluent containing $80 \mathrm{v} / \mathrm{v} \%$ of methanol.The separation efficiency of all columns was determined at the start of the ageing experiments to check anomalous coiumn packing. Due to a more heterogeneous size distribution of the PODCS particles the separation efficiency of all packed columns with the PODCS phase was 3 to $5 \%$ lower than that of the identically packed ODCS columns. The chromatograms of the alkylbenzene test mixture before and after the simulated ageing experiments 1,5 and 6 of the PODCS reversed phase are depicted in Figure 6. A typical diagram of $\log \mathrm{k}^{\prime}$ versus the volume fraction methanol $(x)$ and the incremental carbon number of test mixture $1\left(n_{c}\right)$ is depicted in Figure 7. From this type of diagram the linear dependence of the $\log k^{\prime}$ values on the eluent composition and at the same time on the incremental carbon number of the solutes is clearly shown. According to Eq. (2) and (3), previously published by our group [6], the $a_{0}, m_{0}, a_{1}$ and $m_{1}$ values were calibrated by multiple linear regression. The validity of this regression was controlled by the correlation coefficient (r). By the use of Eq. (5a) and (5b) [6] the derived values for $p$ and $q$ were calculated. 

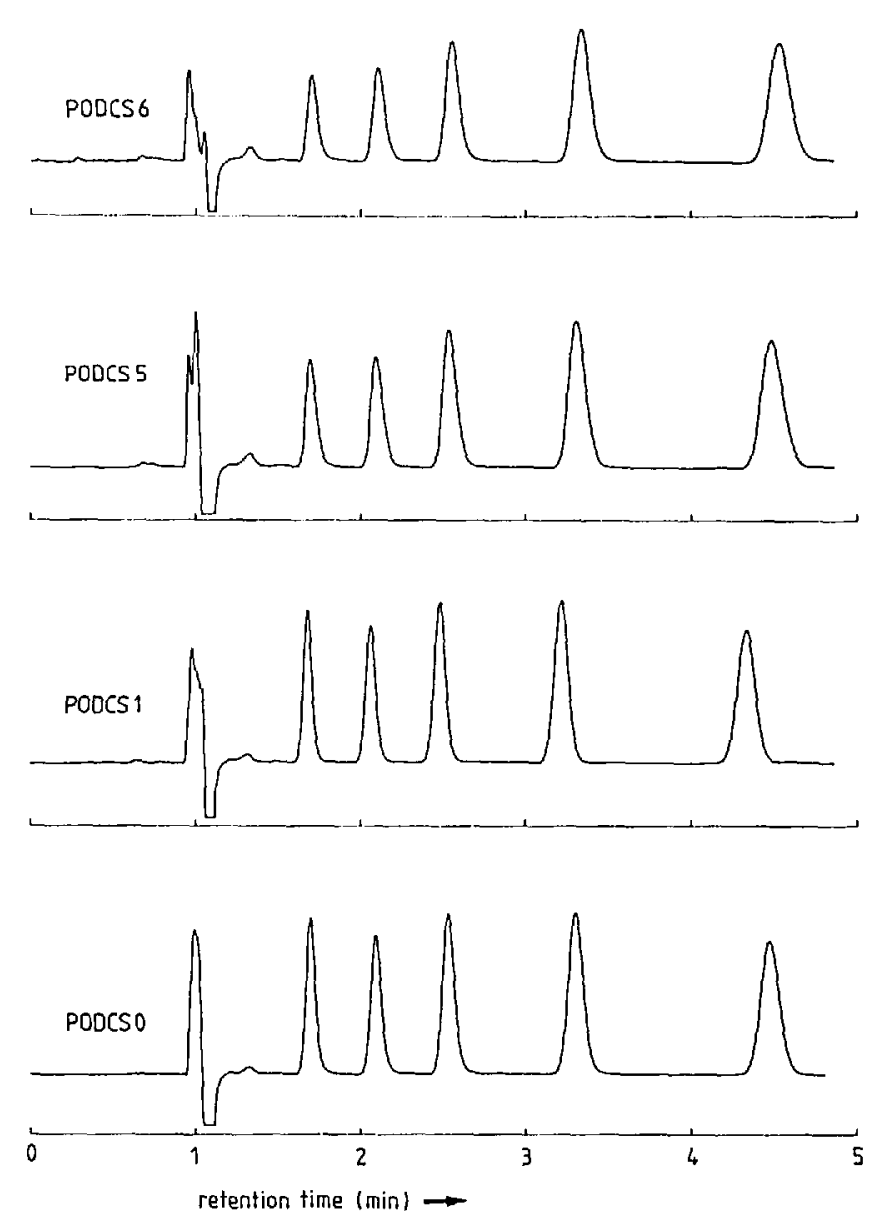

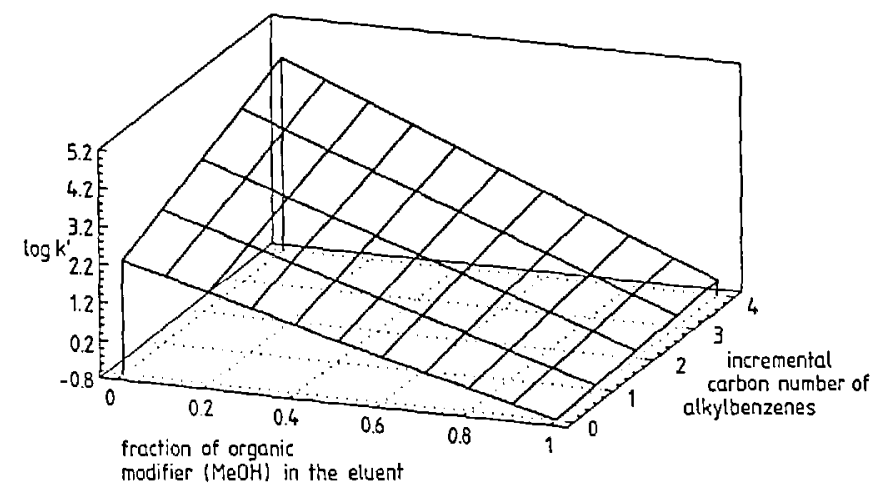

Figure 7

Graphical representation of the regression function for $\mathrm{k}^{\prime}$ with the volume fraction of the organic modifier (in this case methanol) in the eluent between $x=0.6$ and 0.9 and extrapolated for $x$ between 0 and 1 vs. the incremental carbon number of the alkylbenzene homologue series for the PODCS phase after ageing experiment 3.

Figure 6

Chromatograms of the alkylbenzene test mixture on the pretreated octadecyl Chromspher phase belore (0) and after ageing (experiments 1,5 and 6). Chromatographic conditions: methanolwater $80: 20(\mathrm{v} / \mathrm{v}) \%$, UV detection $254 \mathrm{~nm}$.

Table VI Chromatographic characterization parameters, determined with regression and the correlation coefficient for regression for the alkylbenzene homologous series on the ODCS phase before and after each ageing experiment. Experimental conditions as outlined in Table III.

\begin{tabular}{|ccccccc|}
\hline & $\mathrm{a} 0$ & $\mathrm{~m}_{0}$ & $\mathrm{p}$ & $\mathrm{q}$ & $\mathrm{r}$ & $\mathrm{N}$ (Sys) (1) \\
\hline ODCS0 & 2.11 & 2.84 & .829 & 1.09 & .996 & 7164 \\
ODCS1 & 2.26 & 3.05 & .841 & 1.15 & .997 & 6670 \\
ODCS2 & 2.23 & 3.00 & .843 & 1.12 & .996 & 6664 \\
ODCS3 & 2.22 & 2.97 & .850 & 1.08 & .997 & 6022 \\
ODCS5 & 2.04 & 2.76 & .838 & 1.05 & .996 & 5796 \\
ODCS6 & 1.93 & 2.60 & .852 & 0.96 & .996 & 5122 \\
\hline
\end{tabular}

(1) Determined for butylbenzene eluted with an eluent containing $80(\mathrm{v} / \mathrm{v}) \%$ of methanol. Before the ageing experiments columns 1 to 6 showed separation efficiencies of $N($ sys $)=6800 \pm 200$.

Table VII Chromatographic characterization parameters, determined by regression and the correlation coefficient for regression for the alkyl aryl ketone homologous series on the ODCS phase before and after each ageing experiment. Experimental conditions as outlined in Table III.

\begin{tabular}{|lccccc|}
\hline & $\mathrm{a}_{0}$ & $\mathrm{~m}_{0}$ & $\mathrm{p}$ & $\mathrm{q}$ & $\mathrm{r}$ \\
\hline ODCS0 & .362 & 1.54 & .827 & 1.24 & .996 \\
ODCS1 & .557 & 1.81 & .828 & 1.35 & .997 \\
ODCS2 & .414 & 1.61 & .840 & 1.26 & .995 \\
ODCS3 & .329 & 1.50 & .852 & 1.22 & .996 \\
ODCS5 & .183 & 1.33 & .837 & 1.18 & .995 \\
ODCS6 & .458 & 1.60 & .833 & 1.22 & .996 \\
\hline
\end{tabular}


Table VIII Chromatographic characterization parameters, determined by regression and the correlation coefficient for regression for the alkylbenzene homologous series on the PODCS phase before and after each ageing experiment. Experimental conditions as outlined in Table III.

\begin{tabular}{|lcccccc|}
\hline & $\mathrm{a}_{0}$ & $\mathrm{~m}_{0}$ & $\mathrm{p}$ & $\mathrm{q}$ & $\mathrm{r}$ & $\mathrm{N}$ (Sys) (1) \\
\hline PODCS0 & 2.04 & 2.79 & .834 & 1.09 & .996 & 6946 \\
PODCS1 & 2.02 & 2.80 & .820 & 1.13 & .997 & 6605 \\
PODCS2 & 2.20 & 2.96 & .824 & 1.14 & .997 & 5427 \\
PODCS3 & 2.19 & 2.98 & .820 & 1.17 & .997 & 6032 \\
PODCS5 & 2.00 & 2.71 & .842 & 1.03 & .996 & 6384 \\
PODCS6 & 2.06 & 2.84 & .818 & 1.12 & .997 & 6467 \\
\hline
\end{tabular}

(1) Determined for butylbenzene eluted with an eluent containing $80(\mathrm{v} / \mathrm{v}) \%$ of methanol. Before ageing experiments columns 1 to 6 showed scparation efficiencies of $N$ (sys) $=6600 \pm 200$, except the PODCS2 column with $\mathrm{N}$ (sys) $=5950$.

Table IX Chromatographic characterization parameters, determined by regression and the correlation coefficient for regression for the alkyl aryl ketone homologous series on the PODCS phase before and after each ageing experiment. Experimental conditions as outlined in Table III.

\begin{tabular}{|cccccc|}
\hline & $\mathrm{a}_{0}$ & $\mathrm{~m}_{0}$ & $\mathrm{p}$ & $\mathrm{q}$ & $\mathrm{r}$ \\
\hline PODCS0 & .203 & 1.40 & .833 & 1.23 & .995 \\
PODCS1 & .330 & 1.61 & .810 & 1.34 & .997 \\
PODCS2 & .179 & 1.35 & .836 & 1.20 & .995 \\
PODCS3 & .490 & 1.74 & .807 & 1.34 & .996 \\
PODCS5 & .209 & 1.37 & .838 & 1.19 & .997 \\
PODCS6 & .309 & 1.58 & .811 & 1.33 & .996 \\
\hline
\end{tabular}

Tables VI and VII summarize the values for $\mathrm{a}_{0}, \mathrm{~m}_{0}, \mathrm{p}, \mathrm{q}$ and $r$ determined for both test mixtures used before and after each ageing experiment for the ODCS phase, respectively. Tables VIII and IX summarize these values for the PODCS phases. All correlation coefficients were between 0.995 and 0.998 , indicating very reliable values for all constants estimated by use of the regression model used in this study. An exception are the stationary phases after ageing experiment 4 . The eluent used with this experiment apparently caused a severe loss of ligands because of its aggressive nature. A reliable determination of $k^{\prime}$ values was impossible due to extreme band broadening and peak splitting. The value of $a_{0}$ of a relatively apolar residue like benzene, listed in Tables VI and VIII for the OCDS and PODCS phases respectively, represents the capacity factor of these stationary phases.

As expected, the separation efficiency of both stationary phases decreased after prolonged exposure to relatively aggressive eluents. For the ageing experiments with low $\mathrm{pH}$ aqueous and aqueousmethanol buffer solutions the drop in separation efficiency indicates normal changes in the structure of the packed bed. Nevertheless, the capacity factors of the test solutes increased, as will be discussed later (see "Selectivity").

After ageing experiments of the ODCS phase with high $\mathrm{pH}$ eluents the capacity factors for all test solutes decreased and a severe drop in separation efficiency and resolution was found. On the other hand the PODCS phase exhibited almost constant capacity factors and separation efficiency under identical ageing conditons. It can be concluded from these data that the PODCS phase is more resistant towards prolonged exposure to relatively high $\mathrm{pH}$ eluents.

However, the CP-behaviour of the PODCS stationary phase was altered by the ageing. The typical CP-curves with shoulders or double maxima of $\mathrm{M}_{1}, \mathrm{Q}_{3}$ and $\mathrm{Q}_{4}{ }^{29} \mathrm{Si}$ nuclei changed back to an almost normal CPbehaviour as given by the untreated Chromspher silica. Apparently the crystalline regions at the surface of the substrate were destroyed by hydrolysis and only amorphous silica was left, although for aged PODCS phases the $T_{1 \rho H}$ values were still larger than for ODCS phases.

\section{Selectivity}

Selectivity in RP-HPLC depends on both the mobile and the stationary phase. To judge the changes in selectivity of the mobile phase the values for $p$ are listed in Table VI to IX. These values were close to the theoretical value for methanol-water binary eluents calculated by Jandera, $\mathrm{p}=0.86$. More specific stationary phase solute interactions were estimated by the values of $m_{0}$ for lipophilic and $q$ for polar selectivity. As expected, rather good correlations (correlation coefficient values 0.975 and 0.996 for ODCS and PODCS, respectively) were observed between the nonpolar contribution to selectivity $\mathrm{m}_{0}$ and the capacity 
factor of the stationary phase represented by $a_{0}$ values. This is especially true for the most apolar residue of a homologous series of test solutes used in this study, the alkyl benzene test mixture.

However, some unexpected results should be noticed: with decreasing ligand density of the stationary phases (see also the results of elemental analysis and ${ }^{29} \mathrm{Si} \mathrm{CP}$ MAS NMR) the values of $m_{0}$ and $a_{0}$ (alkyl benzenes) increased after all ageing experiments at high $\mathrm{pH}$, indicating increased lipophilic selectivity. It may be concluded that the $a_{0}$ and $m_{0}$ values of the alkylbenzene test mixture were influenced by the high density of the stacked octadecyl ligand chains, especially at the surface of the PODCS phase. Probably due to less densely stacked ligand chains of the original stationary phases this penomenon was not determined in a previous study [6], where $\alpha_{1}$ was about $2.55 \mu \mathrm{mol} \cdot \mathrm{m}^{-2}$. In our opinion, only part of the densely stacked $\mathrm{C}_{18}$ ligands of the stationary phase before ageing were accessible for apolar interaction. After the ageing experiments with high $\mathrm{pH}$ aqueousmethanol buffer solutions the lipophilic selectivity decreased for the ODCS phase, indicating less resistance towards hydrolysis for the ODCS phases.

The fluctuation in polar selectivity, $q$, showed the limited influence of the silanol groups, present at the surface, probably due to steric hindrance by densely stacked ligand chains. For both test mixtures no serious increase of the $q$ values was noticed. Even for the separation of more polar compounds, such as alkyl aryl ketones, the value of $q$ did not change significantly after prolonged exposure to relatively aggressive eluents.

\section{Conclusions}

After the hydrothermal acidic treatment of a silica gel with a relatively high level of ionic impurities, such as the experimental Chromspher silica gel used in this study, small crystalline regions, $\beta$-tridymite-like, will be present at the silica surface. This study shows that after this acid treated silica gel is subjected to monofunctional modification with octadecyl silanes it still contained a considerable amount of crystalline regions and the $\mathrm{CP}$-curves of the ${ }^{29} \mathrm{Si}$ nuclei involved showed the typical double domain behaviour. However, after simulated ageing experiments the crystalline regions disappeared due to substrate hydrolysis. It can be concluded that the crystalline regions were formed close to the substrate surface and were destroyed by hydrolysis.

After the hydrothermal treatment with a $0.1(\mathrm{w} / \mathrm{w}) \%$ hydrofluoric acid solution the silica surface also contained about $12 \%$ more geminal silanol groups, which show a higher intrinsic reactivity upon modification with silanes. Modification of pretreated silica substrate with DMA-DMODS gave a $30 \%$ higher octadecylsilane ligand density, which is presumed to be due to better accessibility of the silica surface inside the pores.

The resulting PODCS reversed phase exhibited a better resistance towards hydrolysis of the chemically bonded ligands, especially when aqueous-methanol buffer solutions with high $\mathrm{pH}$ were used in the ageing treatments. The higher ligand density on the PODCS phase remained more or less constant during simulated routine use and showed a significantly better performance in all the characterization procedures used in this study.

\section{References}

[1] II. A Claessens, C. A. Cramers, J.W. de Haan, F. A. H den Otter, L. J. M. van de Ven, P. J. Andree, G. J. de Jong, N. Lammers, J. Wyma, J. Zeeman, Chromatographia, 20, 582-586 (1985).

[2] J. Köhler, D. B. Chase, R. D. Farlee, A. J. Vega, J. J. Kirk land, J. Chromatogr., 352, 275-305 (1986).

[3] J. Köhler, J. J. Kirkland, J. Chromatogr., 385, 125-150 (1987).

[4] H. A. Claessens, J. W. de Haan, L. J. M. van de Ven, P. C. de Bruijn, C. A. Cramers, J. Chromatogr, 436, 345-365 (1988).

[5] N. Sagliano Jr., R. A. Hartwick, R. E. Patterson, B. A. Woods, J. L. Bass, N. T. Miller, J. Chromatogr. 458, 225-240 (1988).

[6] M. Hetem, L. van de Ven, J. de Haan, C. Cramers, K. Albert, E. Bayer, J. Chromatogr, 479, 269-295 (1989).

[7] K. Szabo, N. L. Ha, P. Schneider, P. Zeltner, E. sz. Kovats, Helv. Chim. Acta, 67, 2128-2142 (1984).

[8] K. D. Lork, K. K. Unger, J. N. Kinkel, J. Chromatogr. 352, 199-211 (1986)

[9] K. D. Lork, Thesis, Johannes Gutenberg University, Mainz, FRG, 1988.

[10] F. J. Feher, D. A. Newman, J. F. Walzer, J. Am. Chem. Soc., 111, 1741-1748 (1989).

[11] B. Pfleiderer, K. Albert, E. Bayer, L. van de Ven, J. de Haan, C. Cramers, J. Phys. Chem., in press.

[12] G. E. Maciel, D.W. Sindorf, J. Am. Chcm. Soc., 102, 7607$7608(1980)$.

Received: Jan. 15, 1990 Accepted: Jan. 31, 1990 B 